\title{
Promoting development with low achievement grouping students in Taiwan
}

\author{
Hsu, Tsu-Chia $\bowtie$ \\ Lunghwa University of Science and Technology, Taiwan, ROC (hsuinuk@gmail.com)
}

Received: 26 December 2011

Revised: 23 January 2012

Available Online: 25 January 2012

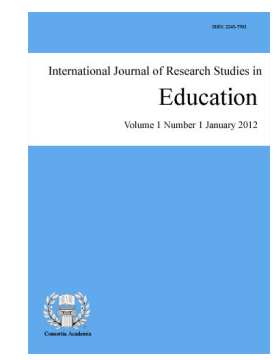

ISSN: 2243-7703 Online ISSN: 2243-7711

OPEN ACCESS

\section{Abstract}

It is hypothesized that students who are categorized in the C-level (low level) Achievement Grouping (AG) in English instruction classes did not necessarily performed at their peak potential in English language competence. Furthermore, it is assumed that the underlying concepts behind the low achievement levels may lies in two assumptions. First, Brophy (2004) addressed the situation with four categories of students based upon how expectancy-related motivational problems might cause students to develop low expectations for themselves. Second, the concept involving the use of AG, might have cause some of the more capable students to lower their achievement levels in English. In response, an action research was accomplished using a Cooperative Task-Based Learning (CTBL) model, based on the concept of learning motivation for students with low achievement levels in an attempt to enhance the students' English competencies. To evaluate the effectiveness of such teaching methodology, data were collected in the form of interview accounts, self-reflective logs, field notes, observations, and students' work sheets. Results show that numerous positive outcomes from both the teachers' and the students' perspectives were noted from the use of the CTBL. In addition, results also show that cooperative group work has proven to be an effective learning strategy. Lastly, useful implications based on the findings were given to shed light on issues regarding the positive effects of skilled-based curriculum designs.

Keywords: low achiever; cooperative learning; task based learning; achievement grouping; second language motivational factors 


\section{Promoting development with low achievement grouping students in Taiwan}

\section{Introduction}

In order to upgrade Taiwan's national competitiveness in the global market, the government has advocated the enhancement of individual English language competence within its educational policy. It is argued that an individual that possessed good English proficiencies can be more effective in meeting life's challenges (Ministry of Education, 2006). Furthermore, following Taiwan's entry into the World Trade Organization (WTO) in 2002, it became essential that as Taiwan being part of the global village to use English to engage in economic cooperation and trade exchanges (Lin, 2005).

Few years ago, the senior executive of the Higher Education Department in Taiwan's Ministry of Education stated that half of Taiwan's college and university students should be able to pass at least the beginning level GEPT (General English Proficiency Test) before 2007; others need to pass intermediate level GEPT as a benchmark upon graduation. Despite the fact that university students in Taiwan are not succeeding in English, GEPT has thus become a gateway as a pass to employment success before college graduation. In particular, the reading and listening units at any level of the test, determine whether applicants can take further exams. In essence, such issues resulted in making reading courses a very important factor in higher educational systems of teaching and learning.

In view of the trend of globalization and educational reform in Taiwan's higher education, the number of students enrolled in colleges and universities has been increasing. For instance, ten years ago the total number of these institutions was 84 and more than half of them were universities. However, the number of universities has grown by nearly $200 \%$, with a total of 147 institutions (not including 16 junior colleges) in Taiwan's HE system (Ministry of Education, 2007). To date, the total number of individuals in Taiwan's higher education during 2006-2007 is approximately 1.3 million amongst a total population of approximately 23 million, shifting away from the former elite educational situation. Hence, Taiwan's HE system needs to upgrade individuals' academic performances and also encourage the concept of teachers (practitioners) as researchers.

\section{Literature review}

\subsection{Achievement group $(A G)$ and students' perception}

Grossen (1996) defines "AG" as "the assignment of students to different classes according to their level of proficiency". By use of this concept it is hoped to bring positive results for both pupils and teachers. The instructors are able to focus on individuals' needs within the same level, and then to choose the best content of teaching materials to suit their pupils' English competencies, which would help in the construction of curricula goals (Luo, 2005). However, AG is not a new idea and it has its problems. For example, there is some international and domestic research, which indicates that AG might cause students to feel negative; thus causing a lack of motivation. This phenomenon is not only apparent when AG is introduced in universities, but also in primary and secondary schools.

In Taiwan, AG problems exist specifically because many Taiwanese elementary and junior high school students feel ashamed about their learning environment once they are placed in basic level classes (Chou \& Luo, 2003). Wang (1998) describes these pupils as disliking the notion of AG being implemented in their learning situations. Ames (1992) also maintains that AG is sometimes perceived as a way of "social comparison" and has been considered as damaging to an individual's motivation. Many low achieving students often disapprove of the idea of being labeled as "low level" according to Wang (1998), and unfortunately, they will be encouraged by this categorization to work toward their "labeled" instead of their "actual" ability. Interestingly, in Taiwan's 
highly competitive learning environment, many of the "better students" disagreed also with the concept of AG since they are placed amongst the "better" students of the class when many of them want to be "the best" student, because many of them feel greater pressure to compete with other "best" students in their classroom (Luo, 2005).

In this paper, two assumptions regarding the cause of low motivation for EFL learners were made. First, there is the issue of students' self-belief and the influence of what is described by Causal Attribution Theory. As stated by Brown (1994), learning motivation is the extent to which an individual makes choices about goals to pursue and the effort one devotes to that objective. Students' belief on how well they can perform and how hard they should work to achieve their goals and even the concern of whether this hard work is worthwhile are significant internal factors that can greatly influence learning outcomes. These circumstances may lead as suggested by Brophy (2004), to four categories of students developing low-expectations for themselves based upon expectancy-related motivational problems. Table 1 as given below clearly presents four categories of students based upon the expectancy-value framework of motivational theories. In addition, considering the high value that Chinese people place upon the maintenance of 'face' a low achievement label could bring a shadow of shame to the family and oneself.

The second assumption is that the use of AG might cause some of the more capable students to lower their achievement levels in English and to behave in a way that they are expected to, that is, to perform according their own label. These phenomena would be predicted by Weiner's (1992) work on Attribution Theory and such internal factors are very likely to cause learners difficulty and discouragement in English reading at the college level.

Table 1

Categories of Students with Expectancy-related Motivational Problems

\begin{tabular}{cl}
\hline Types & \multicolumn{1}{c}{ Description } \\
\hline 1 & $\begin{array}{l}\text { Students with limited abilities, who have difficulty keeping up and who thus develop } \\
\text { chronically low expectations and numbed acceptance of failure. } \\
\text { Students whose failure attributions or ability beliefs make them susceptible to learned } \\
\text { helplessness in failure situations. } \\
\text { Students who are obsessed with self-worth protection and thus focus on performance } \\
\text { goals but not learning goals } \\
\text { Students who underachieve due to their desire to avoid responsibilities. }\end{array}$ \\
\hline
\end{tabular}

Considering the issue of whether there is likely to be a relationship between learners' motivations and their achievements. Some psychologists consider motivation to be one of the crucial determinants of academic achievement and work productivity (Dulay \& Burt, 1977; Keller, 1987). Several domestic studies in Taiwan have also found positive relationships between learners' motivations and their learning achievements (Chang, 2002; Hsu, 1993; Huang, 2004; Liao, 2005; Pan \& Wu, 2004). It is commonly observed that the majority of low achievers possess lower motivations regarding English language learning, particular in the present study of Taiwan, and prior to this study, this researcher observed many low achieving EFL learners in Taiwan's HE AG English classes. The current situation is that a great number of first-year university students in Taiwan get low English scores on their university entrance examinations and are thus placed in low-level AG English instruction classes but still do not perform at their full potential in the English language.

\subsection{The Pedagogy of Cooperative Learning and Task-based Learning Approach}

Cooperative learning (CL) is defined as a teaching method in which members work together toward their learning goals. In so doing, students learn how to work cooperatively and support one another to achieve their objectives in each team. The idea is to help individuals to construct group goals rather than individualistic targets. More importantly, through group work students within EFL class can enhance their communication to achieve 
positive outcomes. This development will then lead to increasing the use of the target language in a meaningful situation (Chafe, 2007). CL indeed can help EFL/ ESL learners to increase their cooperative target language use.

The value of cooperative learning centers on the sharing of work amongst members of a group whose members learn mutually developed skills and competencies and not just from individual work. The notion of using heterogeneous groups arranged by individual academic proficiencies seems to engender some change within CL groups (Allan, 1991; Slavin, 1991); however, there are concerns and worries among practitioners when a group containing low achievers feels threatened by their learning environment (Jacobs, 2006). On the other hand, the mixed group will not feel motivated to persevere to the end. Many studies recommend that lower achievers can receive attention and help through group work (Johnson \& Johnson, 1991). To be specific, low achievers in heterogeneous groups can benefit from their classmates as well as from their teacher (Jacobs, 2006). Furthermore, Johnson \& Johnson (1987) indicate that: "low-achieving students tend to reach higher levels when they are members of heterogeneous CL groups" (p.32) and the researcher utilized this concept to change the entire dynamics in a traditional English-language class.

There have been a number of researchers (Gillies, 2007; Johnson \& Johnson, 1999; Johnson, Johnson, \& Holubec, 1990, 1994) who have widely identified five essential characteristics of CL with a view to forming genuine methodological cooperation (i.e. group investigation) presented in this study. They are: 1.) Positive interdependence; 2.) Face-to-face promotive interaction amongst students; 3.) Individual accountability for mastering the assigned material; 4. Interpersonal and small-group skills used by students; and 5.) Group processing. This type of pedagogy could lead to difficulties for teachers if they just ask the students to work in a group without detailed orientation instruction. In addition, this approach might create negative influences on learners once students work solely in their own group without any appropriate direction. However, a few reviewers (Johnson \& Johnson, 1981; Slavin, 1983, 1989) concerning cooperative learning research are convinced of the effectiveness of learners' achievements through cooperative learning methods as accomplished by individual accountability and group goals within the team's cooperative environment. It is thus worth noting from a wide agreement among reviewers of CL research that the CL method may produce greater positive effects on student achievements (Slavin, 1990).

As indicated by various studies over many decades, CL has demonstrated one effective teaching approach across a diverse curriculum, particularly in the field of a second/ foreign language. In addition, this method helps to meet all needs of individuals in class at all levels with mixed gender and ethnic groups. In addition, the CL approach produces more changes compared to traditional class learning solely by teacher's instructions. Therefore, we must carefully consider these related factors, which might influence learners' successful outcomes prior to use in the second/foreign language classroom. In addition, the communicative language teaching (CLT) approach has highlighted learners' communicative abilities for more than two decades. Since CLT became prevalent, task-based language teaching (TBLT) has become widespread and focused on process-syllabi designing communicative tasks to enable learners to use the target language and practice real-world situation tasks.

A different perspective distinguishes the approaches of language teaching between CLT and TBLT. The CLT approach is derived from psychology, anthropology and linguistics, and represents a global thinking method to teaching language curriculum (Nunan, 2004; Savignon, 1993). Other designs for language curriculum derived from the CLT approach include content-based learning, text-based syllabi, problem-based learning, and immersion education (Nunan, 2004). However, TBLT demonstrates a philosophical reality in providing an opportunity for teaching methods and syllabi designs. In particular, there are three main perspectives of TBLT on language teaching: Second Language Acquisition, Communicative Language Teaching, and Process syllabi (Li, 2004). Some of its supporters consider TBLT as a positive result of CLT because they both share similar standards and have helped to promote the CLT approach since the 80s (Richards \& Rodgers, 2001; Willis, 1996). 
Particularly after the 1980s, courses designed on TBLT received great attention and became known as a 'task-based' approach (Williams \& Burden, 1997). To be specific, based on the notion of the task-based method, TBLT represents "an approach to syllabus design which takes the task as its basic unit". Amongst most 'task-based' theorists, Willis (1996) believes that a task on this approach results in a specific outcome in a classroom. Here, she echoes a similar notion that L2 learners use the target language in a communicative task and its aim is to generate an outcome through meaning exchanges. Therefore, the central notion of meaning in TBLT is to achieve the 'outcome.' In his 1998 work Skehan (1998) also highlights a similar few basic elements of a task as defined by Willis (1996). These elements suggested by Skehan (1998) include that meaning is primarily focused, a goal to be achieved, an outcome of activity to be evaluated, and a real-world activity related to the class task, etc.

Despite the multiplicity of explanations and interpretations of 'tasks' from a number of theorists and researchers, all the definitions of 'tasks' are seen as requiring a purpose of communication (goal), leading to an effective outcome (i.e. using the target language), meaning focus, encouraging learners' engaging and thinking, and practice in real-world class activities. Therefore, using innovative methods with a focus on cooperative task-based learning (CTBL) strategy involving effective group work might be a solution to developing a given student's motivational efforts.

\subsection{The Scope of Motivational Construct and Second Language Learning}

In this study, lower-level university students' motivation to learn in and outside of class is stimulated by the use of the CTBL approach. To be specific, students will be shown to be motivated to learn because of the practice of CTBL approach as mentioned earlier. Particularly with respect to Gardner and Tremblay (1995), the researcher shall provide evidence to enrich their model by adapting it to involve the theories of cooperative learning and the task-based learning teaching approaches. Drawing on aspects of cooperative learning theories, my postulated model will include other variables, as described by cooperative learning theorists, such as Johnson and Johnson. The researcher will describe this model in its entirety in the findings in this study.

The major part of this section CL and TBLT have been shown to promote students' motivation. The second half of the review functions to identify a theory of L2 willingness in order to help conceptualize motivation to read in L2. Gardner and Tremblay's (1995) theory has been shown to be an appropriate choice because it has been carefully developed over many years on the basis of empirical research and also because it incorporates theory and concepts from general motivational psychology. However, Gardner \& Tremblay's extended work has not involved the study of the impact of class-based instruction on motivation to learn. Their model needs to be improved in order to be useful and practical in the classroom. Hence, the researcher combined the concept of cooperative and tasked-based learning/teaching methods in order to enrich the motivational model in the study.

The main research question is as follow: To what extent does a cooperative task-based learning approach, with an emphasis on group work, increase motivation to develop reading skills amongst Taiwanese university students with low achievement levels?

\section{Methodology}

\subsection{Subjects}

The classroom was composed of a female teacher and 19 students (16 males and 3 females) who were from one low-level Achievement grouping EFL classes. The time period, within which the experimentation took place, was a total of nearly 24 hours over 12 weeks. Before the teacher started teaching in practice, she had a lesson where she tried to help the students get to know each other. There was a two-hour introductory session. All participants were from three science departments (departments of Computer Engineering, Chemical Engineering, and Chemistry). 


\subsection{Materials}

Conducting the entire lesson plans and learning activities in this study, the teacher created twelve units as mail weekly topics for the students. Generally speaking, each topic helps learners to reflect about their cultural or social experiences in their own environment, such as weather, leisure activity, transportation, cell phones, MP3s, regional food in Taiwan, business letters, etc. Based on TBLT framework within the cooperative setting, students would try to obtain their group or personal goals, and thus were striving to achieve the given tasks set by the teacher in their group work.

\subsection{Procedures}

Prior to this study, the teacher gave lectures to the students in the previous academic semester. Toward the semester-end the teacher issued a questionnaire aimed at seeking students' attitudes towards learning English in a cooperative learning setting. The majority of potential participants in the study actively revealed their interests in forming cooperative learning groups in the following semester. According to students' positive responses to the teacher's demonstration of one session before the formal study for participants, some students' perceived group learning activities as increasingly stimulating their interests and attention in English learning. Some felt that group learning helped their reading skills and language learning efficiency within given time limits; while others would like to learn more from their peers' problem solving strategies within a groups-setting class and we reached a wide agreement concerning the positive effects from the participants through the initial workshop. In the following semester, the teacher implemented a CTBL approach with a focus on team-work for an approximate 12-week group consisting of 19 volunteer students.

The teacher also created as a first lesson the introduction of the cooperative learning method and task-based learning approach to the class. In the first session, five cooperative learning groups were established. Three or four students depending on their GEPT (General English Proficiency Test) scores formed a team, which we then mixed with students gaining both the highest and lowest scores assigned to each group. The other two students in each group had received the mid-score out of the pre-test based on their GEPT results. Before this introductory session ended, team members exchanged their groups' ideas about how they would work together by integrating their team work, presenting a group task generated from their own team discussion, and serving within the context of their group rules for the rest of the semester. In the following twelve sessions, each group member committed to follow the rules upon which they had already agreed.

In order to examine these processes more closely it was necessary to employ a wide variety of research techniques, which were focused on classroom observation and observation of videotaped lessons from students' and teacher's field diaries as well as research assistant's logs. Data were collected over 12 weeks so that changes over time, such as changes in awareness of group differences, could be identified.

Triangulation was an essential step before the researcher took further action regarding data analysis of this study and this action was necessary to establish credible data and to enhance trustworthiness of the study. All relevant sources for data analysis include self-reflective logs, related observation group sheets, and interview accounts. It is expected that a number of diverse variables will have affected members' motivation through the intervention of the CTBL approach. These variables are considered to be motivating factors for second language students learning to read in a second or foreign language. In drawing conclusions from this model I will refer to the creation of a model building on Gardner and Tremblay's (1995) work.

\subsection{Observation}

The researcher made observations through 12 weeks concerning the degree of awareness changes and she made notes immediately after a course was taught. She subsequently expanded upon and recorded these notes. The classroom was observed for about 100 minutes per session over an average of 12 sessions throughout the whole semester. 


\section{Results and discussion}

In brief, the researcher proposed a model (see figure 1) that good CTBL group work helps create group cohesion and group efficacy, and that these two variables, group cohesion and group efficacy, influence each other within dimension one (also see figure 1). Then, group cohesion and group efficacy both directly lead to positive attitudes toward the learning situation (including the teacher, classmates, and reading activities). In addition, the researcher hypothesized a pleasant CTBL group working experience as being crucial for the learners to enjoy their group tasks in a cooperative learning environment. It directly empowers the members' learning attitudes toward their learning situation and also develops group dynamics and reinforces members' strong incentives, in order to work together towards the same objective.

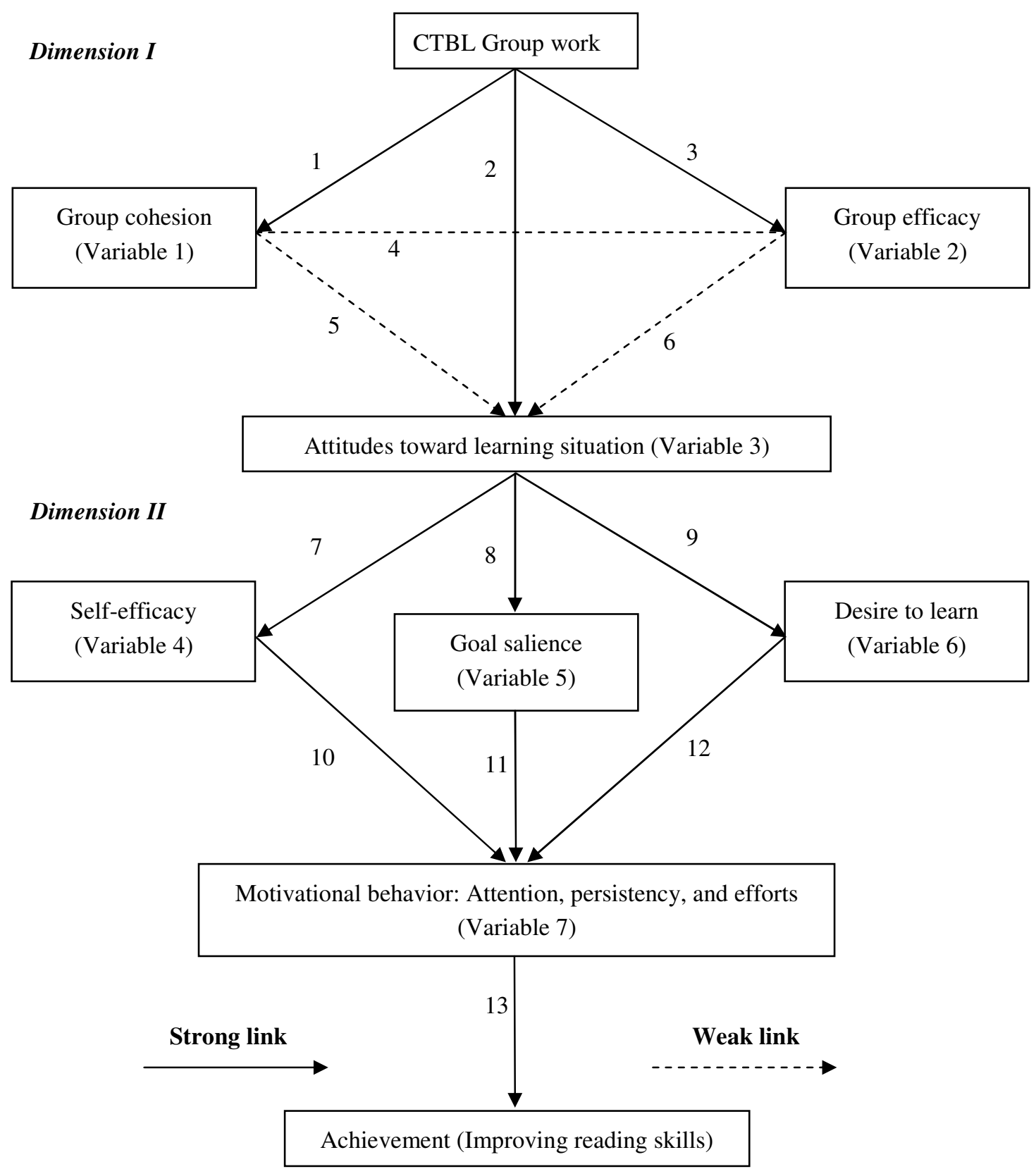

Numbers 1-13: Variables which are derived from the data, concerning motivation of an individual's decision to read in a foreign language. The solid lines (i.e. line 1-3 and 7-13) reflect strong influences, while the broken lines (i.e. line 4-6) reflect weaker influences. A revised model adapted from Gardner and Tremblay's (1995) theory.

Figure 1. Motivation for Foreign Language reading in CTBL Study 
In addition, positive attitudes toward learning situations create three other variables, self-efficacy, goal setting and the desire to improve knowledge. These components cause motivational behavior, such as attention, persistency, and exertion of efforts to learn. The ultimate result of this diagram leads to L2 achievement in reading skills as students report that they improve their reading. In this investigation, I have attempted to account for strong and weak links, and direct or indirect relationships amongst all variables. It is a causal-link model, and all variables relate to one another in the study.

\subsection{Motivation for Foreign Language reading in CTBL Study Model}

\subsubsection{Group Cohesion caused by the CTBL strategy (no.1)}

The following case represents the relationship between group cohesion and CTBL technique:
"I feel that (CTBL group work) could help one another and seek answers together...CTBL group work could motivate (us) to discuss. In addition, (CTBL group reading) is less boring. For example, I could feel greater contextual understanding of given material through group reading." (Male Respondent in post-course interview, DaTong)

DaTong stated the advantages of his CTBL experience by saying he felt the sense of linking of the members to one another by stating, "(it) could help one another and seek answers together." Apart from that, he also brought up an important point that, "it could motivate us to participate in team discussions." Providing one's own opinions to others in group discussions is a must to developing team cohesion and this point also suggests that good team work requires verbal discussions in group. In addition, within group work DaTong felt "less bored" while reading in a group, and he also made an explicit comparison between individual and group reading in favour of the latter: "I could feel more understanding" all because he could associate his good group learning experience with the help of other members through CTBL.

4.1.2 Analysis of the relationship between CTBL and Members' Attitudes toward the learning situation (no.2)

In the following case, the respondent, Hong, could tell to what extent his positive attitudes toward learning developed from experiencing good CTBL group work:

“... and (CTBL group work) is less boring than self study. For example, the individual could not quite understand the meaning of the reading content when one read on his own." (Focus Group

2, Male Respondent in post-course interview, Hong)

This interviewee, Hong, also responded that he would feel rather bored while reading on his own rather than as part of a CTBL group reading class. By implication, CTBL group work can thus help the individual feel more motivated to learn and to understand better the meaning of the reading material.

Another interviewee, Joe, expressed his viewpoint with regards to his perception of CTBL group work as follows:

\footnotetext{
"Reading speed to me is faster than before ... Reading (in a group) helps me to retain the material longer than reading on my own. That is to say the opinions of my fellow team members would remain in my memory longer." (Focus Group 1 in post-course interview, Male, Joe)
}

Joe also said that his reading speed improved during group learning sessions. Through CTBL group work, he could store other members' opinions in his memory when he/ she discussed his/ her thoughts within the group thus helping him to comprehend the reading content better. By implication, Joe agreed with Hong's opinion concerning CTBL group work meaning that good CTBL teamwork will bring better understanding and longer retention capabilities to learners. 


\subsection{Students Experiencing the Relationship between CTBL and Class Teamwork}

The following section concerns recognizing to what extent there exists a relationship between CTBL group work and interactions among classmates:

"Group discussions with others seem much faster and efficient than ever. It can also help us to get acquainted with one another by interactions concerning the reading curriculum." (Chen, Male Respondent in post-course interview)

Via CTBL group work, Chen felt he received positive results by saying, "Group discussions with others seem much faster and more efficient than ever." In addition, he could make friends via these group discussions within the process of reading. By implication, good CTBL group work helps him to engage in group discussion and also to make friends with others.

Another respondent; Yue, had a similar experience with that of Chen:

"Members got along well with one another. (We) had lunch together after class." (Male Respondent in post-course interview, Yue)

Among the best results of CTBL group work, Yue replied that "(We) would have lunch together after class because members of our group could work well and get along with one another." Effective CTBL group work thus creates positive relationships among members in-and-out of class.

Another group echoed the previous respondents while commenting on the results of their teamwork:

We talked to others and we did our best. (Observation group sheet, Group C, week 1)

By implication, there is a cause and effect relationship between CTBL group work and the interfacings of group members.

\subsection{Students Experiencing CTBL activities/tasks}

Focus on the relationship among CTBL group work, reading activities and tasks. The following respondent, Sheng said concerning CTBL group work and CTBL activities:

"For our group we enjoyed mutual sharing among us to discuss answers through group discussions. We all worked together and helped one another toward the same objective without destructive competition among our team members." (Sheng, Male respondent in post-course interview)

We can thus see group discussions as an activity during which members learn how to assist one another and work together as a whole. By implication in the word 'enjoy', good CTBL group work leads to members' positive feelings towards producing meaningful results through CTBL activities.

Good CTBL group work experiences thus develop team members' positive attitudes toward the learning situation, while motivating the individuals' decisions to read in a foreign language. The abundant evidence we found in existing data supports the relationships between CTBL group work and positive attitudes. It suggests that there is a likelihood of a strong link, as the model in no. 2 of the figure suggests, between the relationship of CTBL Group work and Positive attitudes.

\subsubsection{Analysis of the relationship between CTBL and Group Efficacy (no.3)}

In order to examine the relationship between CTBL and Group Efficacy, the interviewee replied to the question, "What would good CTBL group work bring to your group?" 
"Reading speed to him is faster than before ... Reading (in a group) would help us to achieve longer retention than reading on his/her own." (Focus Group 1 in post-course interview, Male, Joe)

First, Joe said that reading in a group increased his reading speed compared to solo efforts. Second, group reading helped him to maintain longer retention rates. Both of these statements suggest that group reading leads to group efficacy. The better (more cooperative) the group work the higher level of group efficacy reached. Compared to individual reading, Joe felt that group efforts resulted in longer retention rates.

\subsubsection{Analysis of the relationship between Group Cohesion and Group Efficacy (no.4)}

We can see evidence of Group Cohesion and Group Efficacy from a female student's response. She was one of only three females out of nineteen students in this study. Shuhua stated that good group experience through CTBL indeed helped her feel that she belonged to the group and that she would also have a positive effect on her team.

"I found many ways to read and I could directly ask other group members often when I don't understand. Something became easy to ask about, and we often discussed matters in this way . . . In addition we answered some reading questions seemingly much faster than ever." (Female Respondent in post-course interview, Shuhua)

Through the strength of CTBL techniques, Shuhua could find herself motivated to read in as many ways as possible. Her statement implies that good group cohesion resulted from good class reading experiences. She found that "directly asking other group members" could help her reading comprehension better and it was "something easy to ask," and, "something they discussed often" because of members' doubts and questions in their minds.

The sense of ease indicates group cohesion. It seemed natural for her to engage other members of her group by asking them questions via oral discussion thus showing good group cohesion. According to Shuhua, asking members' opinions regarding working as a whole became another way of benefiting from teamwork, which improved group efficacy.

NOTE: (Figure 1: no.5-6) the extant evidence in this case cannot conclusively support the existing relationship among the causal links and thus further research in this area is necessary. Rather the broken lines in this model reflect weaker influences and the data thus is not shown.

4.3.3 Analysis of the relationship between members' attitudes toward the learning situation and self-efficacy (no.7)

The following example demonstrates the student, Fuguai, showing his enjoyment in L2 materials and gaining a sense of self-efficacy:

"The class was interesting for me this day. I could use my imagination to write a story from pictures using whichever comic books I like and I could talk with my team-mates for interesting ideas and to practice my English.” (Fuguai, Student diary, week 3)

Fuguai said that he felt that today's lesson was interesting. He used the word "can" four times while emphasizing his increasing language abilities. For example, he "can" write a story by picture, "can" think of the comic book that he likes, "can" discuss interesting ideas with team mates' and "can" increase his English ability through further use of the language.

Interesting contents in the reading material would increase his competency to develop his learning abilities. In so doing, he would feel "special" (more enthusiastic) towards learning in class. Here we have the concept that his learning abilities increase once positive attitudes towards the reading environment are established. 
4.3.4 Analysis of the Relationship between Members' Attitudes Toward the Learning Situation and Goal Salience (no.8)

The following example shows the task goal stimulated by the members' positive learning attitudes:

In this class we considered it fun to use different transportation means to go any place, and we (our) team discussed which forms of transportation were the most economical We chose cars as being the most reasonable, so I learned more ideas from these discussions. (Yan, Male Student's diary, Week 7)

Yan's team members' attention was thus engaged because of a topic regarding their daily lives, transportation, which made participation fun and interesting. His teacher assigned the students given tasks to complete the group goal, which were to answer the question of what was the most economical amongst all methods of transportation (including cars, taxis, city buses) in case study for this group. Yan's team set goals because of the individual's insight enhanced by interesting activities. In so doing, the members strongly engaged in their group discussions and chose the best answer as their group objective. The implication here is that Yen and his group understood the notion of how group goal setting can reinforce their insights to reach the successful outcomes through their group discussion.

4.3.5 Analysis of the relationship between members' Attitudes toward Learning Situation and the Desire to Learn (no. 9)

The following student, Liang, viewed this class with positive attitudes and this led to his strong "desire to do" the reading activity again:

"Not only did our team write a story, but I wrote one myself. This activity can inspire our thoughts, so I think that this is a very excellent activity. I hope that we can do this again." (Liang,

Male Student's diary, Week 3)

Liang stated that his group had completed a story together and so had he. Because of his positive attitudes towards the reading activities, he stated that, "this is a very excellent activity." Now, he would like to do "this" again which implies that his strong desire to learn towards reading is caused by positive attitudes.

4.3.6 Analysis of the Relationship between Motivational Behavior and Self-efficacy (no.10)

The behavior of 'Being Persistent' and 'Making Efforts' was caused by self-efficacy, as the model in no. 10 of figure 1 suggests:

"I feel (I) can remember vocabulary by reading many times." (Jie, Male Respondent in post-course interview)

Jie said that he 'could remember vocabulary' as long as he would 'read many times.' This statement implied that he is able to better his vocabulary in reading through persistence and spending a good deal of time in studying vocabulary with great effort. He could increase his reading ability if he could recognize more vocabulary. And 'remembering vocabulary' implies helping him read more with a sense of confidence. These senses of one's efficacy and confidence create motivational behaviors.

4.3.7 Analysis of the relationship between Motivational Behavior and Goal Salience (no.11)

The behaviors of 'making efforts' and 'persistence' were derived from Goal Salience, as the model in no. 11 of figure 1 suggests. The following example has shown that goal setting leads to motivational behaviors:

“(We would) discuss assignments. We would discuss English homework and use the time after class, lunch break, or lunch time.” (Jie, Male Respondent in post-course interview) 
Jie set the assignment discussion as the group goal. In addition, he stated that he and other members would discuss the English task outside of class. This statement implies Jie's group would spend a great deal of time after class discussing the English assignment. He and other members would frequently discuss as a group how to complete their weekly assignment. In a way, he would use this time to learn English persistently in order to fulfill his learning goal.

\subsubsection{Analysis of the relationship between Motivational Behavior and Desire to Learn (no.12)}

The behavior of 'Paying Attention' and 'Making efforts' created by desire to learn, as the model in no. 12 of figure 1 suggests. The following student referred to the relation between 'motivational behavior' and 'desire to learn':

"(I) feel I wanted to read a little more English reading after class at home, such as short articles or ads . . . to gain a little more vocabulary.” (Datong, Male Respondent in post-course interview)

Datong reflected that he felt he had desire to learn more English reading while interviewing him after the treatment of CTBL approach. He pointed out that his reading desire was motivated, particularly in "short articles" and "advertisements." In addition, he said that he wanted to "gain a little more vocabulary." This statement implied that he had noticed that he was limited in vocabulary, and paid attention to his needs while reading. 'Paying attention' is considered one of the important motivational behaviors. This factor thus shows the causal link between 'desire to learn' and 'motivational behaviors.' In so doing, Datong's desire to learn created his motivational behaviors to learn more.

4.3.9 The Effect of Enhanced Motivational Behavior on Reading Skills: motivational behavior leads to improved reading skills (no.13)

The students think there is a causal relationship between motivational behaviors and improved reading skills. The following respondent said that his reading skills improved because of his persistence and efforts:

"Using of reading skills is improved the most. It's because (we are) often practiced (reading skills).” (Chen, Male Respondent in post-course interview)

Chen said that his reading skills had improved the most. The quotation implied that he had accomplished his reading achievement by improving his reading skills. His reading skills improved because he practiced them often in class and this point suggested that being persistent (often) and making efforts (practicing) leads to improved reading skills. In addition, another student would echo the above student's view:

"Using of reading skills improved the most because it is often required during reading practices." (Chen, Male Respondent in post-course interview)

Chen said that reading skills had improved the most for him. He emphasized that the class was required to practice reading often. It implied that his reading skills improved the most because the class practicing often (persistence and efforts) had made his reading skills progress the most.

All data given have illustrated the model of motivation to read for L2 learners which I developed from analysis of a larger corpus. The model highlights a number of essential variables adapted from Tremblay and Gardner's model (1995), together with two other variables, Group cohesion and Group efficacy, derived from the data. Two variables mediate the relationship between CTBL group work and Students' positive Language Attitudes. Group cohesion and group efficacy appear as two key causal links as given in dimension 1 of the figure. In dimension 2, many other factors appear between students' positive language attitudes toward their learning environment and Motivational Behavior. Three variables, Goal Salience, Valence, and Self-Efficacy, are the important influences suggested by Gardner and Tremblay's original model, which also explain the data in 
this study. In particular the specific variable, goal salience, focuses on the use of group goals and the frequency of group work, which increases the levels of motivational behavior.

This model also predicts that increasing levels of their motivational behavior (i.e. persistence, attention and effort) directly increase students' achievements. This is certainly the case in the students' own perceptions and how they see the relationships between motivation and achievement. It is clear that when students' motivational behavior is reinforced, it will increase their motivation for achievement in EFL reading. In light of this point, the researcher conclude that the proposed model with L2 reading motivation could be helpful for future teachers students themselves but could be helpful for other teachers to demonstrate the relationships among factors in the classroom and help them to plan their lessons taking these factors into consideration scores to encourage them to increase their achievement to read more.

\section{Conclusions and recommendations}

The designed pedagogical strategy, CTBL, indeed responded to the needs of participants in this study group amongst university students with low achievement levels. The study focuses on improving university learners' successful reinforcement of motivation regarding achievement of English reading skills. Abundant evidence from the data demonstrates learners' positive changes regarding their motivation to learn. The researcher observed many students whose motivational levels increased by the implementation of a CTBL approach, thus showing positive potential for them to improve their reading skills. They reported a cause-and-effect relationship between improved motivation and their improvement in reading skills. However, at the same time, the researcher observed no change in the participants' achievement levels and thus there was no objective evidence to measure their achievements.

In conclusion, the teacher can indeed help low-achieving students in the following: As a teacher, I devoted myself to teaching EFL in Taiwan's HE for several years in order to enhance learners' motivation and confidence to learn. This process included many considerations regarding research methods, techniques, and methods concerning data analyses compared with literature and current policy in Taiwan's HE within the present trend of globalization. My fundamental purpose in this action research project was to seek an effective approach to the teaching of reading, one that will help students to enhance their confidence and motivation in this area. I found the approach most likely to succeed in a teacher's twelve-week implementation of a novel concept involving use of a CTBL strategy.

Findings from this study suggest that there is a strong linkage between learners' motivation and their perceptions of learning success in a CTBL class setting as perceived by students. The integration of cooperative learning (CL) and task-based language teaching (TBLT) in this study enables most low achieving learners of English to develop their interests in reading materials involving their learning environment. This paper suggests that low achievement and poor performance can be improved by introducing a CTBL approach as perceived by the pupils'.

It is hoped that this study will enable more teachers to motivate low-achieving students under proper guidance within an environment involving rapport, which introduces the concept and practice of doing more group work and constructing good relationships amongst one another in order to reach team-learning objectives. Future longitudinal studies related to this thesis will be undertaken which explore further applications of a CTBL approach as a treatment for improving low-achieving university students' learning motivation. We can thus consider this study as a practical starting point for future experiments since my work involved this research solely within an AG class in a Taiwanese university. I most sincerely hope that more students in our AG, who are labeled as "low achieving" EFL adult learners, can enhance their motivation to read more. 


\section{References:}

Allan, S. D. (1991). Ability-grouping research reviews: What do they say about grouping and the gifted? Educational Leadership, 48(6), 60-74.

Ames, C. (1992). Classroom: Goals, structures and student motivation. Journal of Educational Psychology, 267, 267-271.

Brophy, J. (2004). Motivating students to learn (2nd ed.). Mahwah, NJ: Lawrence Erlbaum Associates.

Brown, H. D. (1994). Teaching by principles: An interactive approach to language pedagogy. Englewood Cliffs, NJ: Prentice Hall.

Chafe, A. (2007). Cooperative learning and the second language classroom. Retrieved October 5, 2011, from http://blog.naver.com/PostView.nhn?blogId=seorow\&logNo=40042892503\&redirect=Dlog\&widgetTy peCall=true

Chang, M. M. (2002). The role of intrinsic motivation on English learning. Bulletin of National Pingtung University of Science and Technology, 11(2), 154-159.

Chou, Y. C., \& Luo, B. (2003). Effects of levelled and mixed ability grouping on English learning motivation in Taiwanese elementary education. In 20th international conference on English Teaching and Learning in the Republic of China (pp. 411-420). Taichung: Providence University.

Dulay, H., \& Burt, M. (1977). Remarks on creativity in language acquisition. In M. Burt, H. Dulay \& M. Finnochiaro (Eds.), Viewpoints on English as a second language (pp. 95-126). New York: Regents.

Gardner, R. C., \& Tremblay, P. F. (1995). Expanding the motivation construct in language learning. The Modern Language Journal, 79(4), 505-518. <http://dx.doi.org/10.1111/j.1540-4781.1995.tb05451.x>

Gillies, R. (2007). Cooperative learning: integrating theory and practice. London: Sage Publications.

Grossen, B. (1996). How should we group to achieve excellence with equity? Retrieved April 29, 2003, from http://www.uoregon.edu/ adiep/grp.htm

Hsu, J. M. (1993). The effect of how to enhance junior high school students' motivation with low achievers [In Chinese]. Renwen Shehui Kexue Tongxun, 4(4), 6-14.

Huang, Y. C. (2004). The study of learning motivation, communicative willingness, and communicative frequency amongst university freshman English course in Taiwan [In Chinese]. Unpublished Masteral thesis. Tunghai University.

Jacobs, G. (2006). Issues in implementing cooperative learning. In S. McCafferty, G. Jacobs \& A. Iddings (Eds.), Cooperative learning and second language teaching (pp. 30-48). Cambridge: Cambridge University Press.

Johnson, D. W., \& Johnson, R. T. (1981). Effects of cooperative and individualistic learning experiences on interethnic interaction. Journal of Educational Psychology, 73(3), 444-449. $<$ http://dx.doi.org/10.1037/0022-0663.73.3.444>

Johnson, D. W., \& Johnson, R. T. (1987). Learning together and alone: Cooperative, competitive and individualistic learning (2nd ed.). Boston: Allyn and Bacon.

Johnson, D. W., \& Johnson, R. T. (1991). Cooperative learning: increasing college faculty instructional productivity (Vol. 20). Washington DC: The George Washington University.

Johnson, D. W., \& Johnson, R. T. (1999). Learning together and alone: Cooperative, competitive, and individualistic learning (5th ed.). Massachusetts: Allyn and Bacon.

Johnson, D. W., Johnson, R. T., \& Holubec, E. J. (1990). Circles of learning (3rd ed.). Edina, MN: Interaction Book Company.

Johnson, D. W., Johnson, R. T., \& Holubec, E. J. (1994). Cooperative learning in the classroom. Alexandria, VA: Association for Supervision and Curriculum Development.

Keller, J. M. (1987). Development and the use of ARCS model of instructional design. Journal of Instructional Development, 10(3), 2-10. <http://dx.doi.org/10.1007/BF02905780>

Li, C. (2004). Content and language integrated learning: The Taiwanese indigenous cultural awareness project. Unpublished Masteral thesis. University of Durham.

Liao, H. C. (2005). Effects of implementations of cooperative learning on EFL college students in Taiwan. Paper presented at the Fourth Annual Wenshan International Conference, Taipei.

Lin, W. C. (2005). Are they born equal? A socio-cultural enquiry of Taiwanese secondary school students' Englisng learning. Paper presented at the Socio-cultural theory in Educational Research and Practice, School of Education, University of Manchester.

Luo, B. (2005). Achievement grouping and students' progress in freshman English classes at Feng Chia University. Feng Chia Journal of Humanities and Social Sciences, 11, 254-279.

Ministry of Education. (2006). Plan to develop first-class universities and top-level research centres. Retrieved June 26, 2007, from http://english.moe.gov.tw/ct.asp?xItem=7131\&ctNode=505\&mp=1 
Ministry of Education. (2007). Education in the Republic of China. Retrieved August 28, 2007, from http://english.moe.gov.tw/lp.asp?ctNode=2350\&CtUnit=242\&BaseDSD=7\&mp=12

Nunan, D. (2004). Task-based language teaching. Cambridge: Cambridge University Press. $<$ http://dx.doi.org/10.1017/CBO9780511667336>

Pan, C., \& Wu, H. (2004, April 12-16). The effect of cooperative learning on EFL college freshmen's English reading comprehension, motivation and satisfaction. Paper presented at the Annual meeting at American Educational Research Association, Chicago, USA.

Richards, J. C., \& Rodgers, T. S. (2001). Approaches and methods in language teaching. Cambridge: Cambridge University Press. <http://dx.doi.org/10.1017/CBO9780511667305>

Savignon, S. (1993). Communicative language teaching: The state of the art. In S. Silberstein (Ed.), State of the art TESOL essays. Alexandria VA: TESOL.

Skehan, P. (1998). A cognitive approach to language learning. Oxford: Oxford University Press.

Slavin, R. E. (1983). When does cooperative learning increase student achievement? Psychological Bulletin, 94, 429-445. <http://dx.doi.org/10.1037/0033-2909.94.3.429>

Slavin, R. E. (1989). Slavin replies. Educational Leadership, 46(7), 81.

Slavin, R. E. (1990). Cooperative learning: Theory, research and practice. Englewood Cliffs, NJ: Prentice-Hall.

Slavin, R. E. (1991). Cooperative learning: Theory, research, and practice. New Jersey: Prentice Hall.

Wang, S. P. (1998). A pragmatic study on English teaching in leveled classes at colleges. In English Teaching and Learning 15th Conference (pp. 310-330). Taipei: The Crane Publishing Co., Ltd.

Weiner, B. (1992). Human motivation: Metaphors, theories and research. London: Sage.

Williams, M., \& Burden, R. (1997). Psychology for language teachers: A social constructivist approach. Cambridge: Cambridge University Press.

Willis, J. (1996). A framework for task-based learning. Harlow, UK: Addison Wesley Longman Limited. 
Hsu, T. C. 